\title{
The Ionic Composition of Nasal Fluid and Its Function
}

\author{
William Burke1,2 \\ ${ }^{1}$ Brain Research Laboratory, Discipline of Physiology, and Bosch Institute, University of Sydney, Sydney, \\ Australia \\ ${ }^{2}$ Discipline of Anatomy and Histology, University of Sydney, Sydney, Australia \\ Email: william.burke@sydney.edu.au
}

Received 7 February 2014; revised 10 March 2014; accepted 17 March 2014

Copyright (C 2014 by author and Scientific Research Publishing Inc.

This work is licensed under the Creative Commons Attribution International License (CC BY).

http://creativecommons.org/licenses/by/4.0/

(c) (i) Open Access

\section{Abstract}

The aim of the experiments reported here is to increase our understanding of the function of the nasal fluid. It is generally accepted that the nasal fluid assists in the humidification of the inspired air. It also assists in the capture of inspired particles such as pollen, preventing them getting lodged in the lungs. It is also known to contain antibacterial substances which keep the nose, nasopharynx and respiratory passages relatively free of infection. There are other features of the nasal fluid that are not understood. In cold weather, is it the fluid that collects in the nostrils pure water or nasal fluid? Why does nasal fluid have an exceptionally high potassium concentration? Does nasal fluid secreted during the common cold have the same composition as at other times? My objectives are to try to answer these questions. My method is to collect my nasal fluid in several different ways and have the ionic composition of each determined accurately. My findings are that nasal fluid is similar in composition however it is secreted. In cold weather, if expiration is via the nose, the nasal fluid is diluted by condensed water. The high concentration of potassium in the nasal fluid is not a way of controlling the level of potassium in the body but I suggest that it may assist in maintaining the antibacterial property of the nasal fluid.

\section{Keywords}

Nasal Secretion; High Potassium Content; Secretion in Cold Environment; Antibacterial Role

\section{Introduction}

The nose has many functions and for several functions it relies on its nasal fluid. The nose warms the inspired air and also humidifies it by means of the nasal fluid and by transudation from the superficial capillaries in the nostrils [1]. Probably, a more important role of the nose is to filter the incoming air and prevent small particles 
getting into the lungs. Among the most important small particles are pollen grains. In the lungs, pollen can cause allergic reactions and difficulty in breathing. Small particles are trapped by nasal fluid, especially mucus secretion, and these particles are transported by the mucosal ciliary flow [2]. It's possible that admixture with the serous secretion prevents the nasal fluid becoming too viscous. A very important function of nasal fluid is its antibacterial property [3] [4].

There is a major problem in determining the exact composition of nasal fluid and this accounts for the fact that there is often disagreement between different reports in the literature. Because of the unavoidable evaporation of the nasal fluid, the concentration of its constituents increases over time. There will be more evaporation if breathing is through the nose than through the mouth. There will be more evaporation if the inspired air is dry. There is a continuous secretion of nasal fluid but we don't know precisely how this varies. Even if it compensates for the loss of water, it cannot restore the original concentrations unless it also varies the concentrations in the secretions. A common feature is the creation of solid deposits in the nostrils as a result of evaporation. Such deposits will tend to increase the concentrations in the overlying fluid. Obviously, when collecting a sample of nasal fluid, one should try to avoid fluid that has been in contact with deposits for any appreciable time. However, removing deposits from the nostrils, say with a cotton bud, is liable to stimulate secretion and for some experiments this may be undesirable. Even clipping the nostrils in order to accumulate nasal fluid may also stimulate secretion. Another important feature is that periodically we swallow our nasal fluid and we do this subconsciously. The swallow may contain nasal deposits and so the next secretion may be markedly different. It is often quite difficult to inhibit a swallow.

It is clear from all these considerations that the composition of the nasal fluid is never constant but varies with time and conditions, and, of course, with the method of collection. One of the best ways of collecting a sample of nasal fluid is to place a weighed piece of absorbent paper (e.g. filter paper) in the nostrils and remove after a particular time [5]. However, if secretion is slow, evaporation will occur and concentrations will rise. Probably the best estimate of the composition of nasal fluid is from a sample of nasal fluid immediately after a sneeze because this secretion is relatively large and occurs very rapidly, e.g. $0.2 \mathrm{ml}$ in a few seconds [6].

The aim of this project is to answer the following questions. In all the functions of the nasal fluid, what is the relevance of the ionic composition? Does this vary under different circumstances? Why is there an exceptionally high concentration of potassium in nasal fluid? What is the composition of nasal fluid secreted at low temperature?

\section{Methods}

The results in this paper were obtained solely from the author. Nasal fluid was collected mostly by the use of a small spoon of either plastic or stainless steel, about $10 \mathrm{~mm} \times 5 \mathrm{~mm} \times 2 \mathrm{~mm}$, and placed as soon as possible in a microcentrifuge tube with lid of $1.5 \mathrm{ml}$ volume or less which is kept closed. Occasionally fluid was collected by means of a small device made of stainless steel which clipped onto the septum between the nostrils and allowed the fluid to siphon into a microtube. This was only used to collect fluid from a sneeze, otherwise too much fluid was lost by evaporation.

All samples of nasal fluid were analysed by PaLMS (Pacific Laboratory Medicine Services), Royal North Shore Hospital, Sydney. Sodium, potassium and chloride were analysed by ion-selective electrodes (Roche Modular or Abbott Architect). Biarbonate, urea, calcium, magnesium and phosphate were analysed by the methods designed by ARCHITECT eSystens and AEROSET System JCT.

Nasal fluid secreted at low temperature was collected either in a cold room at $\sim 4^{\circ} \mathrm{C}$ in the Department of Physiology, University of Sydney or in the Climate Chamber at $\sim 4^{\circ} \mathrm{C}$ in the Faculty of Health Sciences, University of Sydney.

A total of 21 samples were collected, distributed as shown in the various Tables. The only criterion for accepting a sample was that its volume should be at least $0.25 \mathrm{ml}$. There were no other criteria.

Wilcoxon signed rank tests were used for all statistical tests.

The project was approved by the Human Ethics Administration, University of Sydney (Project No: 2012/2479).

\section{Results}

\subsection{A comparison of Nasal Fluids Obtained in Different Ways}

Regardless of how nasal fluid is created, does it always have the same composition? I collected nasal fluid in 
four different ways: 1) as a spontaneous secretion; 2) resulting from a sneeze; 3) as secreted during a common cold; 4) during a low environmental temperature. Table 1 shows the results from these four procedures. The differences between these four sets of results were tested by the Wilcoxon signed rank test. Table 2 shows the ratios of the four methods for each of the elements in the composition of the fluid.

There was no significant difference between any pair of the methods except for the difference between the fluid collected spontaneously and the nasal fluid collected at $4^{\circ} \mathrm{C}$. This difference is most probably explained by the fact that $4^{\circ} \mathrm{C}$ fluid was collected over a period of about one hour and this would have allowed more time for evaporation, so giving higher values for almost all the elements. However, the absence of a significant difference between the other pairs does not necessarily mean that there is no real difference. That is because the number of samples is low and, as explained previously, collection of nasal fluid is subject to several complications (evaporation, swallowing, etc). Samples relating to the common cold were collected at an early stage of the infection. At a later stage all the values were elevated but further samples could not be obtained, so it is necessary to perform more experiments to check this observation. However, my preliminary observation is consistent with the results of Vanthanouvong and Roomans (2004) reporting elevated ion concentrations in patients with common cold or rhinitis [7].

\subsection{A Comparison of Nasal Fluids Data Reported Here with Values in Other Reports}

$\underline{\text { Table } 3}$ summarizes data published in this and six other papers. Some papers express their data as a range of

Table 1. Analyses of nasal fluids collected in different ways.

\begin{tabular}{|c|c|c|c|c|}
\hline & spontaneous (spont) & sneeze (snz) & common cold (cc) & $4^{\circ} \mathrm{C}$ \\
\hline sodium & $184 \pm 37(2)$ & $158.4 \pm 4.80(5)$ & $138.5 \pm 3.50(2)$ & $189 \pm 24.99$ \\
\hline potassium & $32.6 \pm 5.2(2)$ & $40.33 \pm 1.345(3)$ & $31.7 \pm 2.00(2)$ & $38.2 \pm 4.47$ (3) \\
\hline chloride & $217.5 \pm 56.5(2)$ & $163 \pm 8.73(4)$ & $156 \pm 0.0(2)$ & $205.7 \pm 19.8(3)$ \\
\hline bicarbonate & $10 \pm 2.00(2)$ & $24.7 \pm 1.17(5)$ & $17.5 \pm 2.50(2)$ & $11.67 \pm 0.67(3)$ \\
\hline urea & $15.71 \pm 6.00(2)$ & $15.30 \pm 1.90(5)$ & $13.15 \pm 0.15(2)$ & $25.57 \pm 0.33(3)$ \\
\hline calcium & $1.495 \pm 0.27(2)$ & $1.026 \pm 0.025(5)$ & $1.315 \pm 0.05(2)$ & $1.845 \pm 0.10$ \\
\hline magnesium & $0.72 \pm 0.21(2)$ & $0.83 \pm 0.10$ & $0.47 \pm 0.03(2)$ & $1.16 \pm 0.13(3)$ \\
\hline phosphate & $0.73 \pm 0.0(2)$ & $0.80 \pm 0.09$ & $0.72 \pm 0.06$ & $1.31 \pm 0.05$ \\
\hline
\end{tabular}

The spontaneous (spont) values are from samples of nasal fluid for which there was no known stimulus. The data in the last column ( $4^{\circ} \mathrm{C}$ ) are the values obtained at $4^{\circ} \mathrm{C}$ when expiration was via the mouth, not the nose. All values are expressed as mmol/l (means $+/-$ SEM); number of samples in brackets. See Table 2 for statistical analysis of results.

Table 2. Statistical analysis of results in Table 1.

\begin{tabular}{cccccccc}
\hline & spont $/ \mathrm{snz}$ & spont/cc & spont $/ 4^{\circ} \mathrm{C}$ & $\mathrm{snz} / \mathrm{cc}$ & $\mathrm{snz} / 4^{\circ} \mathrm{C}$ & $\mathrm{cc} / 4^{\circ} \mathrm{C}$ \\
\hline sodium & 1.16 & 1.33 & 0.97 & 1.14 & 0.84 & 0.73 \\
potassium & 0.81 & 1.03 & 0.85 & 1.27 & 1.06 & 0.83 \\
chloride & 1.33 & 1.39 & 1.06 & 1.04 & 0.79 & 0.76 \\
bicarbonate & 0.40 & 0.57 & 0.86 & 1.41 & 2.12 & 1.50 \\
urea & 1.03 & 1.19 & 0.61 & 1.16 & 0.60 & 0.51 \\
calcium & 1.46 & 1.14 & 0.81 & 0.78 & 0.56 & 0.71 \\
magnesium & 0.87 & 1.53 & 0.62 & 1.77 & 0.72 & 0.41 \\
phosphate & 0.91 & 1.01 & 0.56 & 1.11 & 0.61 & $\mathrm{~ns}$ & 0.55 \\
& $\mathrm{~ns}$ & $\mathrm{~ns}$ & $*$ & $\mathrm{~ns}$ & $\mathrm{~ns}$ \\
\hline
\end{tabular}

This Table contains the ratios of all pairs of Means for each component. spont $=$ spontaneous; $\operatorname{snz}=$ sneeze; $\mathrm{cc}=\mathrm{common}$ cold; $4^{\circ} \mathrm{C}=$ samples collected at $4^{\circ} \mathrm{C}$. Analysis by Wilcoxon signed rank test, each condition grouped. No test was significant (ns) except for the spont/ $4^{\circ} \mathrm{C}$ comparison $(\mathrm{P}=$ $\left.0.0234 ;{ }^{*}\right)$. 
Table 3. Comparison of published data with nasal fluid ionic concentrations in the current paper.

\begin{tabular}{ccccccccc}
\hline component & A & B & C & D & E & F & G & H \\
\hline sodium & $98-225$ & & $\sim 110$ & $85 \pm 10$ & $127 \pm 6$ & $142 \pm 28$ & $141 \pm 8$ & $138-189$ \\
potassium & $23-68$ & & $\sim 30$ & & $27 \pm 3$ & $43 \pm 10$ & $61 \pm 8$ & $31-40$ \\
calcium & $3-14$ & & & & $5 \pm 1$ & & & $1.0-1.85$ \\
chloride & & $132 \pm 3$ & $\sim 125$ & $108 \pm 5$ & $140 \pm 7$ & $150 \pm 36$ & $170 \pm 12$ & $156-217$ \\
phosphate & $3-7$ & & & & & & & $0.72-1.31$ \\
\hline
\end{tabular}

All data are mmol/l. A: from Lorin et al., 1972 [5]. B: Smith et al. 1996 [8]. C: Knowles et al. 1997 [9]. D: Hull et al. 1998 [10]. E\&F: Vanthanouvong \& Roomans, 2004 [7]. G: Vanthanouvong et al. 2006 [11]. H: data from this paper. Data in A are the range of values. Data in C are approximate values. Data in $\mathrm{H}$ are the range of Means from Table 1. Data in the other columns are the Means +/- SEM.

values, most as means + /- SEMs, one as approximate values. Because I have used four ways of obtaining the data, I have used the range of means from the four ways (column $\mathrm{H}$ ). As explained in the Introduction, it is not surprising that there is a wide range of values. Nevertheless, allowing for this, there is fair agreement between the eight reports. My values for calcium and phosphate are lower than in two other papers but this may be because these two species of ion are present in low amounts and the estimates are therefore less reliable.

It is relevant to note that the papers do not employ the same method for estimating the ionic composition. Indeed, each paper has a different method, except that the data in columns F and G are from the same laboratory using the same method [7] [11]. Even in such ideal circumstances there may be a difference of $30 \%$ or more (e.g. the values for potassium).

\subsection{Effect of Low Environmental Temperature on the Secretion of Nasal Fluid}

It has frequently been noticed that on a cold day there is often an accumulation of nasal fluid in the nostrils. This is usually very watery and has led to the belief that it is simply a condensation of water from the warm expired air passing through the cold nose [1]. However, it is now believed that the cold environment dilates the blood capillaries supplying the nasal glands and this leads to a nasal secretion above normal. I investigated this phenomenon by collecting nasal fluid over a period of about one hour in a cold room or climate chamber at $4^{\circ} \mathrm{C}$. On three occasions I breathed out through the mouth, on three other occasions I breathed out through the nose. The results of the analyses are shown in Table 4.

It is clear that the concentrations of all the substances measured are much lower when the expired air goes through the nose. The difference is significant (Wilcoxon signed ranks test $P=0.008$ for experiment $\mathrm{A} ; P=$ 0.023 for experiment B). Thus, the nasal fluid collected when expiration is via the mouth is closer to normal, whereas nasal fluid when expiration is via the nose is more dilute. I draw two conclusions from this experiment. The first is a confirmation that a cold environment induces a secretion of nasal fluid. The second is that expired air passing through the nostrils loses some of its water content as condensate, as would indeed be required by the laws of physics, and this, added to the nasal secretion, gives a more dilute sample. The results of such an experiment as this will vary according to several factors: the environmental temperature, the anatomy and physiology of the capillaries in the nostrils, the anatomy and physiology of the nose, especially the size of the nose and the sensitivity of the temperature receptors. However, it does not seem to matter whether inspiration is via the mouth or via the nose.

Why is there an increased blood supply to the nose in cold weather? Apart from the increase in nasal fluid, this will also tend to warm the inspired air and maintain a comfortable environment in the chest. The importance of this is not clear.

\subsection{Relevance of High Potassium Concentrations in the Nasal Fluid}

The concentration of potassium $\mathrm{n}$ the nasal fluid is 7 - 10 times of that in the blood plasma [5] [7] [12] but also varies a lot, both within an individual (this paper) and between individuals [5]. Is there any correlation between the concentrations of sodium and potassium in the various samples of nasal fluid? In answering this question it was important to use as broad a selection of data as possible. Figure 1 plots the distribution of sodium and po 


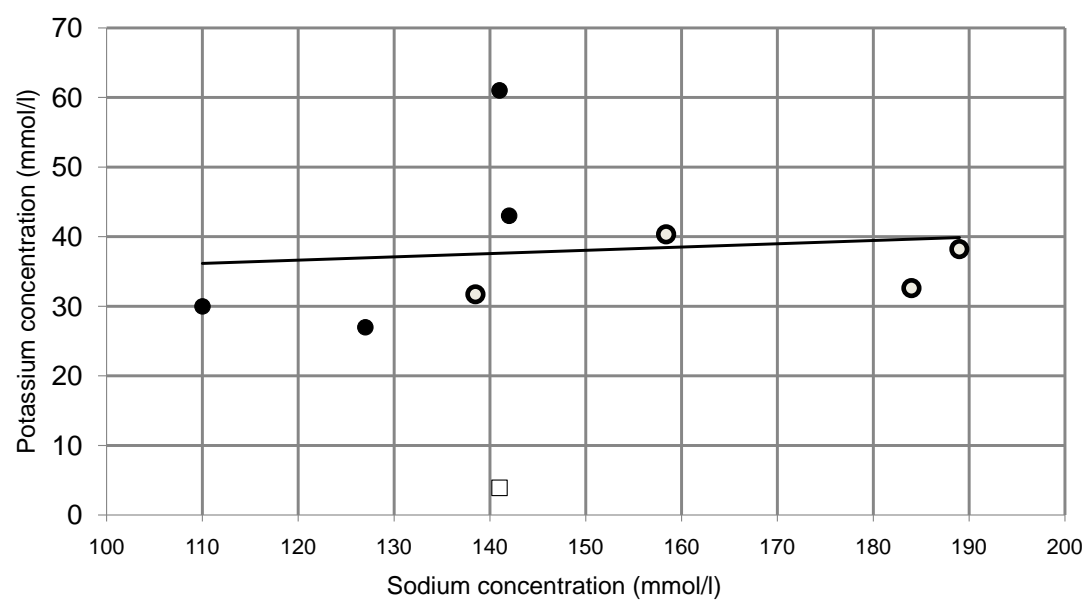

Figure 1. Sodium/potassium relations in nasal fluid and in plasma. The graph plots sodium and potassium concentrations in nasal fluid obtained in the current experiments (open circles; data in Table 1) and in cited papers (filled circles; data in columns C, E, F, G in Table 3). The regression line is based on all the nasal fluid data; note that this is close to the horizontal, indicating an independence of the secretions of sodium and potassium. A single sample from the author depicts the sodium and potassium in his plasma; data similar to textbook values (open rectangle). Note the radical difference between plasma and nasal fluid.

Table 4. Effect of low environmental temperature on nasal secretion.

\begin{tabular}{ccccc} 
& Insp via Mouth & Insp via Nose & Exp & Exp \\
Exp via Nose & A & Exp via Mouth & Nose/Mouth \\
B & Nose/Mouth & A \\
Sodium & $120.7 \pm 10.17(3)$ & $189.0 \pm 24.99(3)$ & 0.6 & 0.86 \\
Potassium & $27 \pm 3.51(3)$ & $38.20 \pm 4.47(3)$ & 0.71 & 0.73 \\
Chloride & $133.7 \pm 12.44(3)$ & $205.7 \pm 19.78(3)$ & 0.65 & 0.86 \\
Bicarbonate & $5 \pm 0(3)$ & $11.67 \pm 0.67(3)$ & 0.43 & 0.45 \\
Urea & $20.75 \pm 3.85(3)$ & $25.57 \pm 0.328(3)$ & 0.81 & 0.55 \\
Calcium & $1.03 \pm 0.102(3)$ & $1.845 \pm 0.105(3)$ & 0.56 & 1.06 \\
Magnesium & $0.87 \pm 0.141(3)$ & $1.16 \pm 0.128(3)$ & 0.75 & 0.73 \\
Phosphate & $1 \pm 0.17(3)$ & $1.313 \pm 0.055(3)$ & 0.76 & 0.95 \\
\hline
\end{tabular}

A. Means $+/-$ SEM of nasal fluid components (mmol/l) obtained at $\sim 4^{\circ} \mathrm{C}$ when inspiring through the Mouth and expiring through the Nose (2nd column) or inspiring through the Nose and expiring through the Mouth (3rd column). The 4th column shows the ratios of the values in the 2nd and 3rd columns. Application of the Wilcoxon signed rank test gives a significant difference $\left(^{* *}\right)$ between the two conditions. $(\mathrm{P}=0.008)$, Figures in brackets are the number of samples. B. In the 5th column are shown the Nose/Mouth ratios from another similar experiment in which inspiration was always through the Mouth: expiration through the Mouth 3 samples; expiration through the Nose 3 samples. Applying the Wilcoxon test showed a significant difference $\left(^{*}\right)$ between the two conditions $(P=0.023)$.

tassium in the nasal fluid obtained in the current experiments (open circles) and also taken from other reports (filled circles); complete data in Tables 1 and 3 . The regression line is drawn through all the nasal fluid data in the graph. It is clear from this that there is no correlation between the concentrations of sodium and potassium, Thus, the factor determining the secretion of potassium is different to that regulating the secretion of sodium.

Also relevant to this conclusion is the difference between the concentrations of these ions in plasma and in nasal fluid. This is illustrated by plotting in the graph the $\mathrm{Na} / \mathrm{K}$ relation for the plasma of the author on one occasion, a value close to the textbook value (open rectangle). The large difference between this and the nasal fluid is clear and this emphasises the particular importance of the potassium in the nasal fluid.

What is the role of the potassium in the nasal fluid? This question will be taken up in the Discussion. 


\section{Discussion}

The results reported here are from a single person, the author. Obviously I cannot claim that they are characteristic of a large population. As I explained in the Introduction there are serious difficulties in getting accurate estimates of the volume and composition of nasal fluid. Therefore, this paper is to a large degree an account of all these difficulties and perhaps some advice about how to avoid serious errors. Although I have tried to avoid such errors, I have not paid any attention to variations in environmental temperature or humidity nor to many subconscious aspects of breathing such as swallowing, sniffing, clearing the throat, etc, all of which might affect the composition of nasal fluid.

\subsection{A Comparison of Nasal Fluids Obtained in Different Ways.}

The results show no convincing evidence that the composition of nasal fluid collected in different ways differed significantly. Even though one pair of methods $\left(\operatorname{spont} / 4^{\circ} \mathrm{C}\right)$ reached a significant difference, this most probably reflects the problems associated with the collection of nasal fluid referred to in the Introduction, in this case the long time required to collect the secretion at $4^{\circ} \mathrm{C}$ with the resultant rise in evaporation. However, I think it is unlikely that there is any dramatic difference between any pair of the secretions.

There is probably no reason why nasal fluid should vary greatly in ionic composition. On the other hand, it would not be surprising if the organic constituents of nasal fluid might vary in concentration. I have examined only urea. Urea is a metabolite of nitrogen-containing foodstuffs and has no physiological function; although it is mainly excreted in the urine, its concentration in nasal fluid might depend on the amount of nitrogen in the diet.

\subsection{Effect of Low Environmental Temperature on the Secretion of Nasal Fluid}

The results obtained here show clearly that the fluid collected from the nostrils in cold weather contains nasal fluid similar to that obtained at normal temperatures. If expiration is via the nose there is a dilution of the nasal fluid, as would be expected if warm air from the lungs passing through a cold nose condenses to water.

Is there a greater secretion of nasal fluid at low temperatures than at room temperatures? I am unable to answer this question. I can collect nasal fluid at room temperatures and such samples are shown in Table 1 as 'spontaneous'. However, I do not know what caused these secretions. I also note, as other people do, that quite often one sneezes, and produces a lot of nasal fluid, for no obvious reason. It is generally believed that such sneezes are caused by an irritation of the nasal mucosa but that such stimulation is not consciously detected. If one breathes always through the nose it is probable that one's nasal secretions pass to the nasopharynx and are swallowed. This would tend to reduce the observed amount of nasal secretion. This factor and all the others mentioned in the Introduction mean that there is considerable uncertainty as to whether there is a difference between the amounts or compositions of nasal fluids collected in different ways. If the cold environment causes a dilation of blood capillaries in the nostrils, the effect on the glands may be fortuitous, not the main effect.

\subsection{Relevance of Ionic Concentrations in the Nasal Fluid}

It is possible that the high potassium fills a role within the nose or the upper airway but such a role has not yet been discovered. It has been known for a long time that the concentrations of the major ions in the nasal fluid are not arbitrary. Fleming (1922) [3] noted that the lysozyme, the antibacterial substance that he discovered in nasal fluid (and other secretions and tissues) acted most rapidly if a small amount of salt (less than $0.1 \% \mathrm{NaCl}$ ) was present but not if the concentration exceeded 5.0\%. This combination of facilitatory and inhibitory effects of salt concentrations has been confirmed many times [13]-[15]. It is clear that nasal fluid has appropriate ionic concentrations to facilitate an antibacterial influence. However, it is possible that some species of ion may play a specific role. For example, cystic fibrosis (CF) is caused by a mutation in the gene regulating chloride conductance in the apical epithelia, leading to elevated chloride concentration in the nasal fluid $(182 \mathrm{mmol} / \mathrm{l}$. vs 132 $\mathrm{mmol} / \mathrm{l}$ in non-CF nasal fluid) [8]. This gene also affects the sodium channel, and the increased chloride concentration, or perhaps the increased $\mathrm{NaCl}$ concentration act specifically to reduce or abolish the bactericidal activity of the CF nasal fluid [8] Most of the discussion on this matter has concentrated on sodium and chloride. The relative importance of other ions does not appear to have been studied. The concentration of potassium in nasal fluid is unusually high at about $35 \mathrm{mmol} / \mathrm{l}$ (Figure 1). This raises the question of the relevance of potassium in 
nasal fluid.

\subsection{Relevance of High Potassium Concentrations in the Nasal Fluid}

It is possible that the high potassium fills a role within the nose or the upper airway but such a role has not yet been discovered. Is it possible that this is a way of excreting potassium from the body? From Harada et al. (1984) [16] one can calculate that in each day about $36 \mathrm{ml}$ of nasal fluid is secreted. Let's assume that all of this swallowed. This contains about $1.4 \mathrm{~g}$ of potassium (about $1.3 \mathrm{mmol}$ ). This is below the lowest amount found in the faeces in cases of low potassium intake [17] and is a small amount compared with the normal excretion of potassium in the urine (40 - $66 \mathrm{mmol} /$ day) or faeces (4 - $16 \mathrm{mmol} /$ day) [17]. Thus it is unlikely that the high concentration of potassium in the nasal fluid is there as a method of controlling the level of potassium in the body. The main control obviously remains with the kidney.

Another possibility is that the potassium contributes to an antibacterial role. It is well known that the nasal fluid has such a property [3] [4] and this must be partly due to the presence of lysozyme and the immunoglobulins, but there are many other antibacterial substances in the nasal fluid [14]. In a different context, potassium is used to reduce infection in food preparations such as processed poultry [18] [19], where the potassium is present as a fatty acid salt. The applied solutions are strongly alkaline ( $\mathrm{pH}$ about 12 ) and it is possible that the antimicrobial effect is partly due to the high $\mathrm{pH}$. In recent years potassium diformate has been used in pigs and other animals as a growth promoter alternative to antibiotics [20] [21]. Potassium diformate is also antibacterial but it is not known whether this effect us due to the low $\mathrm{pH}$, resulting from the free formic acid, or to formate or to the potassium.

In recent years, foods have been coated with edible films that act partly to prevent contamination and to varying degrees are antibacterial. One substance used in these films is potassium sorbate. This seems to work best at low $\mathrm{pH}$ such as $3.0-4.5$ [22]. Again, it is uncertain what the role of the potassium is, and whether this has any relevance to the high potassium in the nasal fluid.

It remains a possibility that potassium has a special influence as an antibacterial supplement, greater than that of the other ions. A recent paper has data that may be relevant [23]. These authors were concerned with the occurrence of ventilator-associated pneumonia (VAP) and chronic lung disease in neonates resulting from airway suctioning, assisted by preliminary instillation of normal saline. They found that replacing the normal saline with a low-sodium solution reduced the incidence of VAP and lung disease. However the low-sodium solution contained $24.5 \mathrm{mmol} / \mathrm{l}$ potassium, i.e. an amount similar to that found in normal nasal fluid (see Table 3). They do not comment on the role of the potassium but its presence (and the absence of any bactericide) prompts the question: does potassium have any antibacterial function in the low-sodium solution and, correspondingly, in nasal fluid.

\section{Conclusion}

However generated, the ionic composition of nasal fluid is similar. The ionic composition is always appropriate for its antibacterial action. Of particular interest is the relatively high concentration of potassium. One possible role for potassium (as a method of controlling the level of potassium in the body) has been rejected. A second role as a facilitator of antibacterial action should be tested.

\section{Acknowledgements}

I thank Dane King for reading an earlier version of the manuscript and offering valuable suggestions for improvement. My thanks are also due to John Dodson, Adel Mitry and Raymond Patton for excellent technical assistance.

\section{Conflicts of Interest}

The author has no conflicts of interest of any kind.

\section{References}

[1] Proctor, D.F. and Adams, III, G.K. (1976) Physiology and Pharmacology of Nasal Function and Mucus Secretion. In: 
Widdicombe, J., Ed., Pharmacology and Therapeutics B. Pergamon, Oxford, Vol 2, 493-509.

[2] Andersen, I., Lundqvist, G.R. and Proctor, D.F. (1971) Human Nasal Mucosal Function in a Controlled Climate. Archives of Environmental Health, 23, 408-420. http://dx.doi.org/10.1080/00039896.1971.10666029

[3] Fleming, A. (1922) On a Remarkable Bacteriolytic Element Found in Tissues and Secretions. Proceedings of the Royal Society of London, Series B, 93, 306-317. http://dx.doi.org/10.1098/rspb.1922.0023

[4] Cole, A.M., Dewan, P. and Ganz, T. (1999) Innate Antimicrobial Activity of nasal secretions. Infection and Immunity, 67, 3267-3275.

[5] Lorin, M.I., Gaerlan, P.F. and Mandel, I.D. (1972) Quantitative Composition of Nasal Secretions in Normal Subjects. Journal of Laboratory and Clinical Medicine, 80, 275-281.

[6] Burke, W. (2012) Why Do We Sneeze? Medical Hypotheses, 78, 502-504. http://dx.doi.org/10.1016/j.mehy.2012.01.017

[7] Vanthanouvong, V. and Roomans, G.M. (2004) Methods for Determining the Composition of Nasal Fluid by X-Ray Microanalysis. Microscopy Research and Technique, 63, 122-128. http://dx.doi.org/10.1002/jemt.20020

[8] Smith, J.J., Travis, S.M., Greenberg, E.P., and Welsh, M.J. (1996) Cystic Fibrosis Airway Epithelia Fail to Kill Bacteria Because of Abnormal Airway Surface Fluid. Cell, 85, 229-236. http://dx.doi.org/10.1016/S0092-8674(00)81099-5

[9] Knowles, M.R., Robinson, J.M., Wood, R.E., Pue, C.A., Mentz, W.M., Wager, G.C., Gatzy, J.T. and Boucher, R.C. (1997) Ion Composition of Airway Surface Liquid of Patients with Cystic Fibrosis Compared with Normal and Disease-Control Subjects. Journal of Clinical Investigation, 100, 2588-2595. http://dx.doi.org/10.1172/JCI119802

[10] Hull, J., Skinner, W., Robertson, C. and Phelan, P. (1998) Elemental Content of Airway Surface Liquid from Infants with Cystic Fibrosis. American Journal of Respiratory and Critical Care Medicine, 157, 10-14. http://dx.doi.org/10.1164/ajrccm.157.1.9703045

[11] Vanthanouvong, V., Kozlova, I., Johannesson, M., Nääs, E., Nordvall, S.L., Dragomir, A. and Roomans, G.M. (2006) Composition of Nasal Airway Surface Liquid in Cystic Fibrosis and Other Airway Diseases Determined by X-Ray Microanalysis. Microscopy Research and Technique, 69, 271-276. http://dx.doi.org/10.1002/jemt.20310

[12] Grubb, B.R., Chadburn, J.L. and Boucher, R.C. (2002) In Vivo Microdialysis for Determination of Nasal Liquid Ion Composition. American Journal of Physiology, Cell Physiolohy, 282, C1423-C1431. http://dx.doi.org/10.1152/ajpcell.00612.2001

[13] Goldman, M.J., Anderson, G.M., Stolzenberg, E.D., Kari, U.P., Zasloff, M. and Wilson, J.M. (1997) Human ß-Defensin-1 Is a Salt-Sensitive Antibiotic in Lung That Is Inactivated in Cystic Fibrosis. Cell, 88, 553-560. http://dx.doi.org/10.1016/S0092-8674(00)81895-4

[14] Singh, P.K., Tack, B.F., McCray, Jr., P.B. and Welsh, M.J. (2000) Synergistic and Additive Killing by Antimicrobial Factors Found in Human Airway Surface Liquid. American journal of physiology. Lung Cellular and Molecular Physiology, 279, L799-L805.

[15] Zabner, J., Seiler, M.P., Launspach, J.L., Karp, P.H., Kearney, W.R., Look, D.C., Smith, J.J. and Welsh, M.J. (2000) The Osmolyte Xylitol Reduces the Salt Concentration of Airway Surface Liquid and May Enhance Bacterial Killing. Proceedings of the National Academy of Sciences of the United States of America, 97, 11614-11619. http://dx.doi.org/10.1073/pnas.97.21.11614

[16] Harada, T., Hamaguchi, Y., Sakakura, Y. and Miyoshi, Y. (1984) Circadian Variation of Secretory IgA in Nasal Secretions from Normal Subjects. Acta Otolaryngologica (Stockh), 97, 359-362. http://dx.doi.org/10.3109/00016488409131000

[17] Klevay, L.M., Bogden, J.D., Aladjem, M., Sandstead, H.H., Kemp, F.W., Li, W., Skarnick, J. and Aviv, A. (2007) Renal and Gastrointestinal Potassium Excretion in Humans: New Insight Based on New Data and Review and Analysis of Published Studies. Journal of the American College of Nutrition, 26, 103-110. http://dx.doi.org/10.1080/07315724.2007.10719591

[18] Hinton, Jr., A. and Ingram, K.D. (2005) Microbicidal Activity of Tripotasium Phosphate and Fatty Acids toward Spoilage and Pathogenic Bacteria Associated with Poultry. Journal of Food Protection, 68, 1462-1466.

[19] Hinton, Jr., A. and Ingram, K.D. (2006) Antimucrobial Activity of Potassium Hydroxide and Lauric Acid against Microorganisms Associated with Poultry Processing. Journal of Food Protection, 69, 1611-1615.

[20] Overland, M., Granli, T., Kjos, N.P., Fjetland, O., Steien, S.H. and Stokstad, M. (2000) Effect of Dietary Formates on Growth Performance, Carcass Traits, Sensory Quality, Intestinal, Microflora, and Stomach Alterations in Growing-Finishing Pigs. Journal of Animal Science, 78, 1875-1884.

[21] Chowdhury, R., Haque, M.N., Islam, M.S. and Khan, M.J. (2008) Potassium Diformate: A New Alternative to Antibiotic Growth Promoters. Bangladesh Journal of Animal Science, 37, 99-105.

[22] Flores, S., Haedo, A.S., Campos, C. and Gerschenson, L. (2007) Antimicrobial Performance of Potassium Sorbate 
Supported in Tapioca Starch Edible Films. European Food Research and Technology, 225, 375-384. http://dx.doi.org/10.1007/s00217-006-0427-5

[23] Christensen, R.D., Henry, E., Baer, V.L., Hoang, N, Snow, G.L., Rigby, G., Burnett, J., Wiedmeier, S.E., Faix, R.G. and Eggert, L.D. (2010) A Low-Sodium Solution for Airway Care: Results of a Multi-Center Trial. Respiratory Care, 55, 1680-1685. 